\title{
Report on Isolation and Identification of Brucella Abortus from Aborted Foetus and Lymph Nodes of Beef Cattle in Malaysia
}

\author{
Zainor M Khairani-Bejo S*, Zunita Z and Bahaman AR \\ Department of Veterinary Pathology and Microbiology, University Putra Malaysia, Malaysia
}

Submission: January 27, 2017; Published: February 06, 2017

*Corresponding author: Zainor M Khairani-Bejo S, Department of Veterinary Pathology and Microbiology, Faculty of Veterinary Medicine, University Putra Malaysia, 43400 UPM, Serdang, Selangor, Malaysia, Tel: 603-86093460; Fax: 603-89471972; Email: skhairani@upm.edu.my

\begin{abstract}
Isolation of living brucellae from tissues or organs such as aborted foetus and lymph nodes has traditionally provided the most accurate method for the detection of Brucella infection. The inoculated medium was incubated at $37{ }^{\circ} \mathrm{C}$ for 7 days with $10 \% \mathrm{CO}_{2}$. Bacterial colonies growth on the agar was examined. The bacterial cells were stained with Gram-staining and Modified Ziehl-Neelsen staining methods and later were examined under microscope to determine their cell morphology. Biochemical tests were performed to complete the phenotypic and metabolic characterisation of the isolates. Brucella abortus were isolated from stomach content, lung and cotyledon of the aborted foetus; and supramammary and internal iliac lymph nodes of aborted cattle. Histopathological examination of lymph nodes found the infiltrations of microphages, neutrophils and giant cells with vacuolated and engorged macrophages scattered in the necrotic debris of supramamarry lymph node of aborted cattle.
\end{abstract}

Keywords: Brucella abortus; Lymph nodes; Aborted foetus; cattle

\section{Introduction}

Brucellosis is an infectious disease caused by Gram -negative facultative intracellular bacterial organisms of the genus Brucella. The organisms are pleomorphic, short, slender coccobacilli and their colonies are small, round, convex, smooth, moist-appearing and translucent. The organisms are pathogenic for a wide variety of animals and human beings. Brucella abortus is identified as a major pathogen of brucellosis in cattle all over the world. The disease usually asymptomatic in non-pregnant females but adult male cattle may develop an orchitis. The organisms localise in various lymph nodes of female cattle such as supramammary, udder, retropharyngeal and mandibular lymph nodes; internal and external iliac lymph nodes; regional lymph nodes and uterus. The most consistent lesion of B. abortus infection in cattle involved the lymph nodes, which were remarkably enlarged and had follicular hyperplasia with a few giant cells and macrophages Forbes et al. [1].

In pregnant animals, placentitis will occurred following infection and abortions usually happened between the fifth and ninth months of the pregnancy. Although serological tests are being used for monitoring the herds, bacteriological isolation is still a gold standard for either screening of the infection or preparing eradication programs Bricker [2]. Direct and accurate diagnosis of brucellosis can be made by microbiologic examination. Currently, identification of $B$. abortus using conventional methods is commonly applied in the diagnosis of brucellosis. These methods provide phenotypic and metabolic characterisations based on microbiological examinations. Biochemical tests have been used to distinguish different biotypes of Brucella species. Thus, the objective of this study was to isolate and identify Brucella abortus from cattle by using biochemical tests and histopathology examination.

Aborted foetus was obtained from cattle which is serological positive to brucellosis as detected by CFT. Stomach content, lung, liver and cotyledon were collected from the aborted foetus. Lymph nodes namely supramammary, mandibular, suprapharyngeal, mesenteric, internal iliac and superficial inguinal were collected from cattle that was slaughtered. Lymph node samples were also collected for histological examination. All samples were kept in ice-box upon transportation to the laboratory.

All samples were handle followed the techniques outline in Manual of diagnostic test and vaccines for terrestrial animal Nielsen \& Ewalt [3]. The samples were inoculated onto Brucella 
agar (Pronadisa, Spain) and McConkey agar (Oxoid, USA). All specimens were processed inside biosafety cabinet. Inoculated agar plates were placed in $\mathrm{CO} 2$ jar and incubated at $37^{\circ} \mathrm{C}$ for 7 days. The growth of Brucella organisms on each agar plate was observed. Brucellae were stained with modified Ziehl-Neelseen staining method and their cell morphology was examined under microscope. Isolated Brucellae were identified and characterized by standard methods as described by Alton et al. [4]. Isolated organisms were identified by biochemical tests such as catalase, oxidase, nitrate reduction, H2S production, urease activity and growth in the presence of thionin and basic fuchsin.

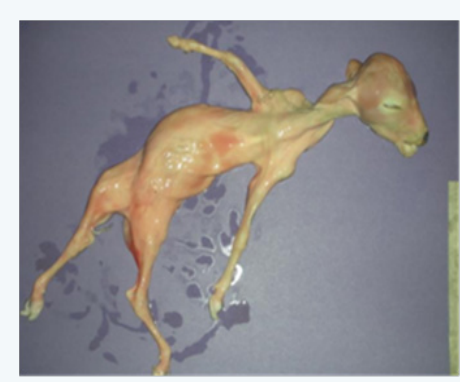

Figure 1: Oedematous with moderate blood-tinged in subcutaneous tissue of aborted foetus.

On post-mortem, the aborted foetus were oedematous with blood-tinged in subcutaneous tissue (Figure 1). The umbilical was thickened and lungs showed fibrinous pneumonia. The abomasal contents were turbid, yellow and flaky. Intercotyledonary placenta was thickened with a yellow gelatinous fluid. The cotyledons were shown mild to moderate hyperaemic (Figure 2).

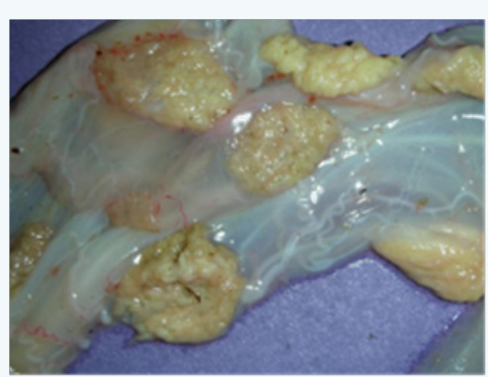

Figure 2: The intercotylydonary placenta was thickened with a yellow gelatinous fluid. The cotyledons were shown mild to moderate hyperaemic.

Brucella abortus were isolated from stomach content, lung and cotyledon of the aborted foetus. The organisms were also isolated from supramammary and internal iliac lymph nodes of slaughtered cattle that was serologically positive to brucellosis. The isolates shown typical characteristic of Brucella abortus. The organisms were grown on Brucella agar but not on McConkey agar. They required carbon dioxide for their growth and the colonies were well grown after seven days incubation at 37 ${ }^{\circ} \mathrm{C}$. The bacterial colonies were raised smooth, dome shape, white in colour, moist-appearing and transparent when viewed towards a light source. The isolates were small Gram-negative coccobacillary cells, present in clumps and stained red by the modified Ziehl-Neelsen staining method. Biochemical tests result showed that, the isolates were growth in TSI agar slant and non-motile. All isolates produced oxidase, catalase and urease. They also reduced nitrates to nitrites and produced hydrogen sulphide. The isolates were grown on agar with additional of basic fuchsin but no growth on agar added with thionin.

The most valuable samples for isolation of Brucellae were included aborted foetuses (stomach contents, spleen and lung), fetal membranes, vaginal swabs, milk and semen. In post-mortem, the suitable samples were lymph nodes such as mammary and genital lymph nodes; and spleen. The supramammary lymph nodes were the best source for isolating brucellae in cattle Sutherland \& Searson [5]. Specimens should be collected as soon as possible following any suspicious abortion or calving. Specimens should be processed as soon as possible. Ideally, transportation systems should ensure that specimens arrive in the laboratory within 24 hours. The procedures used for collecting and transport of specimens from healthy or clinically affected animals or post mortem, are critically important for successful laboratory analyses. These must be done in accordance with current best practice. Carbon dioxide requirement for growth, production of hydrogen sulphide and growth in present of basic fuchsin and thionin were using for confirmation and differentiate between the Brucella species Nielsen \& Ewalt [3]. All isolates were submitted to Veterinary Laboratories Agency (VLA) United Kingdom for further identification and was confirmed as Brucella abortus.

\section{References}

1. Forbes LB, Tessaro SV, Lees W (1996) Experimental studies on Brucella abortus in moose (Alces alces). Journal of Wildlife Disease 32(1): 94104.

2. Bricker BJ (2002) Diagnostic strategies used for the identification of Brucella. Vet Microbiol 90 (1-4): 433-434.

3. Nielsen K, Ewalt DR (2008) Bovine brucellosis. In: Nielsen K, Ewalt (Eds.), DR Manual of Diagnostic Test and Vaccines for Terrestrial Animal, Vol 2: OIE Terrestrial Manual, Paris, France, pp. 624-659.

4. Alton GG, Jones LM, Piezt DE (1975) Laboratory techniques in Brucellosis. Monogr Ser World Health Organ 55: 1-163.

5. Sutherland SS, Searson J (1990) The immune response to Brucella abortus: The humoral response. In: Nielsen K, Duncan JR (Eds.), Animal brucellosis. CRC Press, New York, USA, pp. 66-67. 
This work is licensed under Creative Commons Attribution 4.0 Licens DOI: 10.19080/JDVS.2017.01.555553
Your next submission with Juniper Publishers will reach you the below assets

- Quality Editorial service

- Swift Peer Review

- Reprints availability

- E-prints Service

- Manuscript Podcast for convenient understanding

- Global attainment for your research

- Manuscript accessibility in different formats ( Pdf, E-pub, Full Text, Audio)

- Unceasing customer service

Track the below URL for one-step submission https://juniperpublishers.com/online-submission.php 